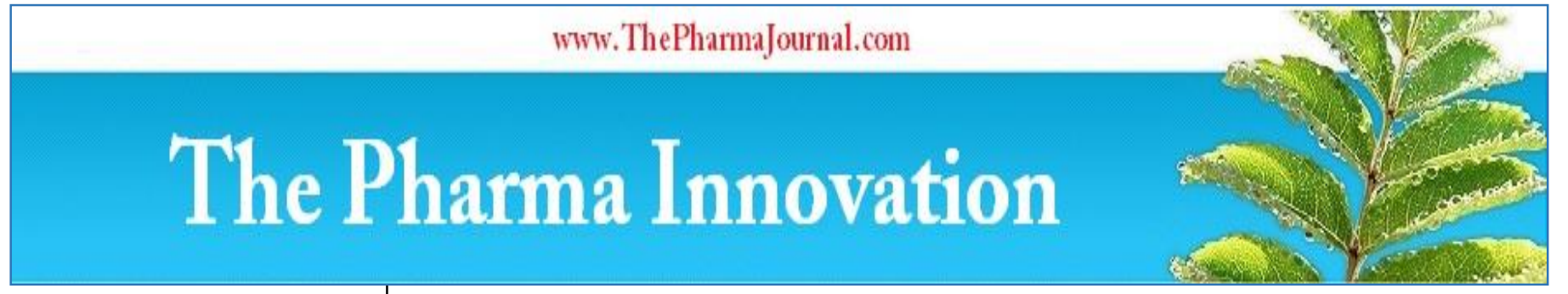

ISSN (E): 2277 - 7695

ISSN (P): 2349-8242

NAAS Rating: 5.23

TPI 2021; 10(4): 250-253

(C) 2021 TPI

www.thepharmajournal.com

Received: 02-01-2021

Accepted: 26-02-2021

\section{Md. Ayesha}

Department of Genetics and Plant Breeding, Agricultural College, Bapatla, Andhra Pradesh, India

\section{Ratna Babu}

Department of Genetics and Plant Breeding, Agricultural College, Bapatla, Andhra

Pradesh, India

\section{A Prasanna Rajesh}

Department of Genetics and Plant Breeding, Agricultural College, Mahanandi, Andhra

Pradesh, India

\section{Lal Ahmed Md}

Department of Genetics and Plant Breeding, Agricultural College, Bapatla, Andhra Pradesh, India

\section{Manoj Kumar}

Department of Plant Pathology, Agricultural College, Bapatla, Andhra Pradesh, India

\title{
Principal components of genetic diversity in black gram [Vigna mungo (L.) Hepper]
}

\section{Md. Ayesha, D Ratna Babu, A Prasanna Rajesh, Lal Ahmed Md and V Manoj Kumar}

DOI: https://doi.org/10.22271/tpi.2021.v10.i4d.5935

\begin{abstract}
Forty black gram [Vigna mungo (L.) Hepper] genotypes were evaluated using principal component analysis to estimate the extent of genetic diversity for ten different yield and its component traits. The first three principal components viz., PC I, PC II and PC III with eigen values more than one contributed around $80 \%$ of the variability for the genotypes studied. PC I contributed $46.834 \%$ towards variability and the traits responsible for its contribution are viz., number of clusters per plant, grain yield per plant, number of branches per plant and number of seeds per pod. The second axis (PC II) contributed $18.951 \%$ variability and variation at this axis is due to the accumulated genetic variation of traits viz., days to $50 \%$ flowering, days to maturity, grain yield per plant and number of clusters per plant. While PC III and PC IV accumulated $13.807 \%$ and $5.765 \%$ respectively. Therefore on a cumulative note, first four axes contributed about $85.357 \%$ of total variance among 10 characters for all the forty genotypes under study. In the current investigation, four lines (TU 94-2, PU 31, IPU 94-1 and LBG 623) are identified from the depicted 2D \& 3D figures as diverse genotypes, which may yield transgressive segregants or heterotic $\mathrm{F}_{1} \mathrm{~s}$ based on nature of gene action of the trait in question.
\end{abstract}

Keywords: Genetic diversity, Eigen value, principal components, black gram, Vigna mungo

\section{Introduction}

Black gram (Vigna mungo (L.) Hepper) is one of the important pulse crops in India. It is a short duration, self-pollinated and diploid grain legume $(2 n=2 x=22)$. It is believed that black gram was domesticated from a wild progenitor of Vigna mungo var. silvestris in India (Kaewwongwal et al., 2015) ${ }^{[1]}$. Black gram seeds have high nutritive value with protein (25$26 \%$ ), carbohydrates $(60 \%)$, fat $(1.5 \%)$, minerals, amino acids and vitamins (Singh and Singh, 2013) ${ }^{[2]}$. It is also one of the important kharif and spring/summer pulse crop of many South Asian countries like of India, Pakistan, Nepal, Bangladesh, Thailand and Korea (Ghafoor and Arshad, 2008) ${ }^{[3]}$. In spite of its importance, the productivity of this crop is relatively low. India is the largest producer and consumer of black gram. The annual production of black gram in India is 3060 thousand tonnes from 5602 thousand hectares with an average productivity of $546 \mathrm{~kg} / \mathrm{ha}$, while in Andhra Pradesh it is grown in an area of 318 thousand hectares with a production of 310.56 thousand tonnes and productivity of around $977 \mathrm{~kg} / \mathrm{ha}$. (Ministry of Agriculture, 2018) ${ }^{[4]}$. The major constraints in achieving higher productivity are lack of exploitable genetic variability, absence of suitable ideotype, poor harvest index, susceptibility to biotic and abiotic stresses, non-availability of quality seeds of improved varieties and narrow genetic base which occur due to repeated usage of few parents with high degree of relatedness in crossing programmes (Hadimani et al., 2016) ${ }^{[5]}$. In order to improve yield, new black gram varieties must be developed. An assessment of the genetic diversity of pulses is an important initial step in any research programme to improve crop yield. Multivariate analysis such as principal component analysis (PCA) and cluster analysis serve as potential tools in evaluating the phenotypic diversity, identifying genetically distant clusters of genotypes and selecting important traits contributing to the total variation in the genotypes. These analyses provide information that could help in better selection of parental genotypes with specific traits and in devising breeding strategies for trait improvement. Principal component analysis (PCA) allows natural grouping of the genotypes and is precise indicator of differences among genotypes. PCA is very helpful for identification of plant characters that categorize the distinctiveness among promising genotypes (Chakravorty et al., 2013) ${ }^{[6]}$.

\section{Corresponding
D Ratna Babu}

Department of Genetics and Plant Breeding, Agricultural College, Bapatla, Andhra Pradesh, India 
Principal component analysis (PCA) and two-way cluster analysis are two important statistical programs that aid in selecting elite genotypes for breeding programme that meet the goal of a breeder for the development of improved varieties (Mohammadi and Prasanna, 2003) ${ }^{[7]}$. To address the requirement of identifying diverse lines, forty black gram genotypes were evaluated by PCA to identify genetically diverse genotypes and to identify traits that contribute to variability in the population.

\section{Materials and Methods}

Forty genotypes of black gram obtained from various research stations viz., RARS Lam, ARS Gantasala and Baba Atomic Research Centre (BARC) were evaluated in Randomised Complete Block Design with three replications during Kharif, 2019 at Advanced PG Centre, Lam, Guntur. Each genotype was raised in two rows of three meter length with a spacing of $30 \times 10 \mathrm{~cm}$ between and within the rows, respectively. Observations on yield component traits viz., plant height, number of branches per plant, number of clusters per plant, number of pods per plant, pod length, number of seeds per pod, test weight and grain yield per plant were recorded on randomly selected five plants per replication and their mean values were subjected to statistical analysis. However, observations on days to $50 \%$ flowering and days to maturity were recorded on plot basis. PCA was carried out to know the stages of divergence and the traits contributing at each stage or axis towards diversity and principal component scores were used as variables instead of attributes for clustering procedures, thereby making the results equivalent to those from initially standardized data as the correlation matrix was used for its study. In PCA on correlation matrix, the standardization of columns (here characters) created 10 new variables for 40 genotypes without changing their relative positions. All these 10 new variables are the principal components (PCI, PCII .......PC X) and each principal component is a linear combination of the 10 attributes of data matrix. The loading values are scaled or standardized in such a manner that the sum of square of loadings within a principal component is equal to one and these loadings are viewed as weights defining the contribution of characters in respective principal component. Like regression coefficients, loadings sign (+ / -) are indicative of the direction of contribution. But unlike regression, only the relative contributions are important, so all signs can be changed without affecting the analysis (Jackson, 1991) ${ }^{[8]}$.

The loadings for first principal component were chosen so as to make its variance as large as possible. Loadings of second principal component were chosen such that the variance of PC II is as large as possible, subject to the constraint that PC I and PC II are uncorrelated. The process was continued to create 10 principal components, but PC's having eigen value less than one is not having any practical significance (Legendre and Legendre, 1984) ${ }^{[9]}$

Results obtained from PCA on the correlation matrix of the traits reduce the dimensionality of the data set by creating several significant principal components having Eigen value more than one. The PCA scores for individual genotypes were used for clustering the genotypes as suggested by Anderberg (1993) ${ }^{[10]}$. Results of PCA and cluster analysis are discussed here under.

\section{Results and Discussion}

The differentiation occurred in any population at during different evolutionary stages, is represented by different axes and these axes together represent total divergence. A certain proportion of total variability is created at each stage of differentiation or axis. To understand this differentiation, variances (Eigen values), variability in \%, cumulatively accumulated variability and component loading of the 10 different traits were estimated and presented in Table 1. Nearly $80 \%$ of the variation in the genotypes studied for 10 polygenic traits was due to 1 st three components (PC I, II, III) having eigen values greater than unity. And partitioning of total variance through principal component analysis showed that the first four principal components contributed 85.357 percent towards the total variability (Table 1).

Table 1: Eigen values, cumulative percent variance and component loading of first four principal components for traits in black gram

\begin{tabular}{|c|c|c|c|c|}
\hline & PC I & PC II & PC III & PC IV \\
\hline Eugene Value (Root) & 4.683 & 1.895 & 1.381 & 0.576 \\
\hline \% Var. Exp. & 46.834 & 18.951 & 13.807 & 5.765 \\
\hline Cum. Var. Exp. & 46.834 & 65.785 & 79.592 & 85.357 \\
\hline Days to 50\% flowering & 0.014 & 0.649 & 0.295 & 0.030 \\
\hline Plant height (cm) & 0.191 & -0.175 & 0.618 & -0.595 \\
\hline Number of branches per plant & 0.379 & -0.208 & -0.175 & -0.356 \\
\hline Number of clusters per plant & 0.397 & 0.104 & -0.316 & 0.004 \\
\hline Number of pods per plant & 0.318 & -0.043 & -0.441 & -0.242 \\
\hline Pod length (cm) & 0.369 & -0.059 & 0.158 & 0.550 \\
\hline Number of seeds per pod & 0.374 & -0.196 & 0.243 & 0.099 \\
\hline Test weight (g) & 0.352 & 0.043 & 0.323 & 0.229 \\
\hline Days to maturity & 0.118 & 0.636 & -0.060 & -0.294 \\
\hline Grain yield per plant (g) & 0.384 & 0.210 & -0.119 & 0.098 \\
\hline
\end{tabular}

The first principal component (PC I) contributed $46.834 \%$ towards variability. Characters viz., number of clusters per plant (0.397), grain yield per plant (0.384), number of branches per plant (0.379) and number of seeds per pod (0.374) explained the maximum variance in this component. The second axis (PC II) contributed 18.951 percent variability and variation at this axis is because of accumulated genetic variation of traits viz., days to $50 \%$ flowering (0.649), days to maturity (0.636), grain yield per plant $(0.210)$ and number of clusters per plant (0.104). PC III contributed 13.807 percent of heritable variation and has significant positive loadings of plant height (0.618), test weight $(0.323)$ and days to 50 percent flowering (0.295). And the fourth principal component (PC IV) was characterized by 5.765 percent contribution towards the total variability. This axis showed positive loadings for pod length (0.550), test weight (0.229) and number of seeds per pod (0.099). The cumulative variability percentage for first component is 46.834 , while it 
is 65.785 for PC II, 79.592 for PC III and 85.357 for PC IV. The PCA scores for 40 black gram genotypes in the first three principal components were computed and were considered as three axes as $\mathrm{X}, \mathrm{Y}$ and $\mathrm{Z}$ and squared distance of each genotype from these three axes were calculated (Table 2).

Table 2: PCA scores of respective vectors for 40 black gram genotypes

\begin{tabular}{|c|c|c|c|c|}
\hline S. No. & Genotype & $\begin{array}{c}\text { PC I } \\
\text { X vector }\end{array}$ & $\begin{array}{c}\text { PC II } \\
\text { Y vetor }\end{array}$ & $\begin{array}{c}\text { PC III } \\
\text { Z vector }\end{array}$ \\
\hline 1 & MBG 1053 & 21.173 & 19.647 & 13.664 \\
\hline 2 & TBG 106 & 26.494 & 23.376 & 9.585 \\
\hline 3 & GKB 2 & 24.074 & 21.181 & 13.035 \\
\hline 4 & PU 31 & 21.033 & 19.452 & 10.341 \\
\hline 5 & PU 212 & 20.087 & 20.901 & 16.994 \\
\hline 6 & TBG 104 & 23.779 & 20.092 & 13.380 \\
\hline 7 & VBG 4-008 & 22.173 & 20.601 & 13.148 \\
\hline 8 & VBG 14-016 & 24.829 & 22.819 & 14.158 \\
\hline 9 & GKB 4 & 22.390 & 21.131 & 12.154 \\
\hline 10 & VBG 13-003 & 26.393 & 20.830 & 12.817 \\
\hline 11 & MBG 1046 & 25.908 & 22.019 & 11.250 \\
\hline 12 & VBG 4-14 & 24.808 & 19.960 & 13.897 \\
\hline 13 & GAVT 12 & 27.722 & 20.069 & 9.500 \\
\hline 14 & GKB 3 & 22.121 & 20.057 & 13.376 \\
\hline 15 & MBG 1050 & 24.940 & 21.211 & 13.628 \\
\hline 16 & GBG 12 & 28.278 & 25.173 & 11.168 \\
\hline 17 & LBG 20 & 24.179 & 19.961 & 14.889 \\
\hline 18 & LBG 787 & 21.642 & 24.677 & 15.933 \\
\hline 19 & GAVT 7 & 28.500 & 22.906 & 9.740 \\
\hline 20 & GKB 1 & 22.224 & 19.515 & 17.068 \\
\hline 21 & LBG 726 & 19.599 & 20.384 & 14.769 \\
\hline 22 & LBG 752 & 21.925 & 23.695 & 15.603 \\
\hline 23 & LBG 771 & 20.170 & 20.287 & 17.701 \\
\hline 24 & VBG 12-110 & 21.974 & 20.791 & 13.004 \\
\hline 25 & MBG 1069 & 23.594 & 20.226 & 14.091 \\
\hline 26 & GBG 1 & 23.911 & 20.990 & 13.041 \\
\hline 27 & LBG 623 & 21.926 & 23.308 & 16.264 \\
\hline 28 & MBG 207 & 17.438 & 20.960 & 13.235 \\
\hline 29 & VAMBAN 8 & 16.034 & 19.771 & 13.104 \\
\hline 30 & UAHS BG 1 & 19.685 & 25.560 & 13.928 \\
\hline 31 & UAHS BG 7 & 24.333 & 24.683 & 11.731 \\
\hline 32 & UAHS BG 8 & 22.204 & 25.677 & 11.543 \\
\hline 33 & UAHS BG 2 & 18.877 & 23.083 & 13.116 \\
\hline 34 & UAHS BG 3 & 25.326 & 24.456 & 14.342 \\
\hline 35 & UAHS BG 6 & 17.762 & 21.311 & 15.038 \\
\hline 36 & IPU 7-3 & 17.166 & 24.868 & 13.352 \\
\hline 38 & IPU 94-1 & 16.734 & 21.501 & 11.230 \\
\hline IPU 2-43 & 23.960 & 25.194 & 13.208 \\
\hline TU 94-2 & 20.017 & 21.950 & 11.140 \\
\hline KPU 26 & 17.097 & 20.459 & 13.786 \\
\hline
\end{tabular}

These three PCA scores for 40 genotypes were plotted in graph to get two dimensional and three dimensional scatter diagrams (Fig 1\&2) for the studied genotypes. The diverse genotypes numbered 4 (PU 31), 27 (LBG 623), 37 (IPU 94-1) and 39 (TU 94-2), which are far apart from each other in the 2 dimension \& 3 dimension diagram (Fig 1\&2) may result in hybrid combinations to exploit the heterosis or to produce transgressive segregants in their respective $F_{2}$ and subsequent segregation generation. Similar usage of PCA for obtaining 2D \& 3D diagrams and inturn to understand the genetic diversity was earlier employed in various crops Jadhav et al.,
$2014^{[11]}$ in finger millet; Naik et al., $2016^{[12]}$ in cotton; Priya et al., $2017^{[13]}$ in rice; Ayesha and Babu., $2018^{[14]}$ in foxtail millet and Priya et al., $2019^{[15]}$ in mung bean to indicate the successful hybrid combination to obtain superior hybrids or transgressive segregants depending on the gene action guiding different traits.

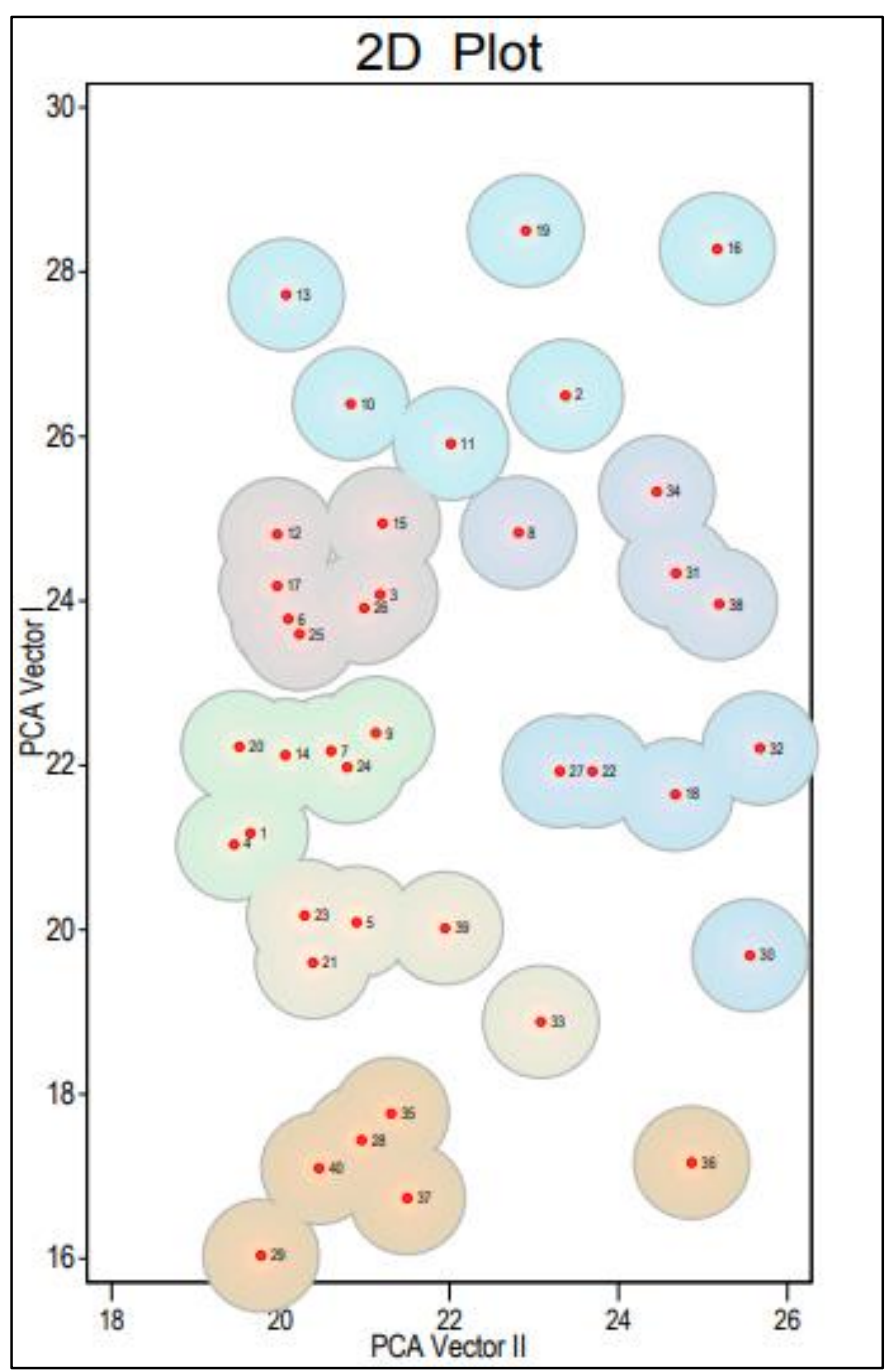

Fig 1: Two dimensional graph showing relative positions of 40 black gram genotypes based on PCA scores

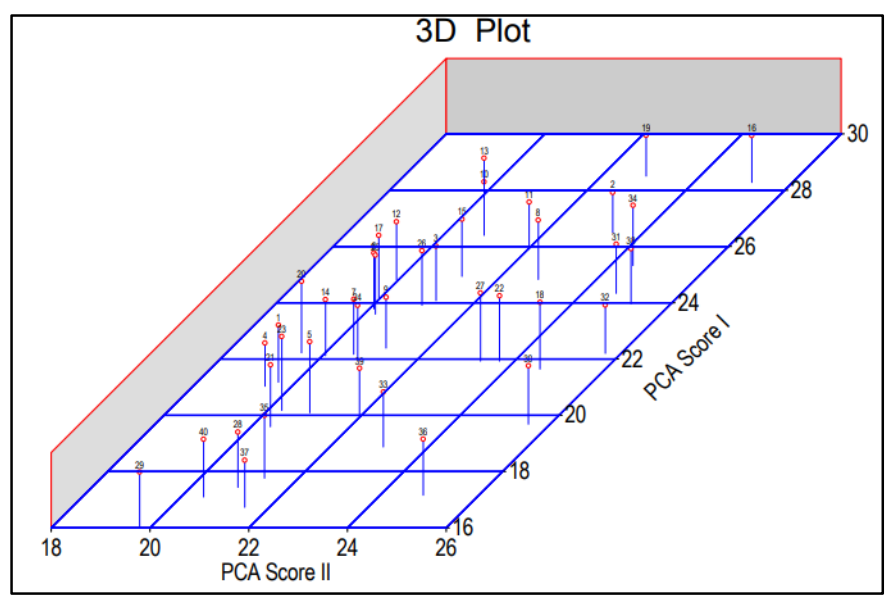

Fig 2: Three dimensional graph showing relative positions of 40 black gram genotypes based on PCA scores

\section{References}

1. Kaewwongwal A, Kongjaimun A, Somta P, Chankaew S, 
Yimram T, Srinivas P. Genetic diversity of black gram (Vigna mungo (L.) Hepper) gene revealed by SSR markers. Breed Sci 2015;65(2):127-137.

2. Singh SK, Singh GC. Effect of phosphorus, sulphur and zinc on nutrient composition in Black gram. The Journal of Rural and Agricultural Research 2013;13(2): 63,64.

3. Ghafoor A, Arshad M. Multivariate analyses for quantitative traits to determine genetic diversity of black gram [Vigna mungo (L.) Hepper] germplasm. Pak. J Bot 2008;40:2307-2313.

4. Ministry of Agriculture. Government of India 2018. http:// www.indiastat.com

5. Hadimani A, Konda CR, Nidagundi JM, Patil R. Genetic diversity analysis in black gram (Vigna mungo (L.) Hepper) based on quantitative traits. Green Farming 2016;7(3):598-601.

6. Chakravorty A, Ghosh PD, Sahu PK. Multivariate analysis of landraces of rice of West Bengal. American Journal of Experimental Agriculture 2013;3(1):110-123.

7. Mohammadi SA, Prasanna BM. Analysis of genetic diversity in crop plants, salient statistical tools and considerations. Crop Sci 2003;43:235-48.

8. Jackson JE. A User's Guide to Principal Components. John Wiley and Sons Inc., New York 1991.

9. Legendre L, Legendre P. Ecologia Numerique. Presses de I’Universite du Quebec 1984;Xv+260p, viii+335,

10. Anderberg MR. Cluster analysis for application. Academic Press, New York 1993.

11. Jadhav R, Babu DR, Ahamed ML, Rao VS. Assessment of genetic divergence in Finger millet [Eleusine coracana (L.) Gaertn.] for yield and yield contributing traits. Intl. J. Food. Ferment. Technol 2014;4(2):113-120.

12. Naik BM, Satish Y, Babu DR. Genetic diversity analysis in American cotton (Gossypium hirsutum L.). Electron. J. Plant Breed 2016;7(4):1002-1006.

13. Priya ChS, Suneetha Y, Babu DR, Rao VS. Assessment of Genetic Diversity for Grain Yield and Quality Traits in Rice (Oryza sativa L.) Using Principal Component Analysis. AAJ 2017;64(3):562-566.

14. Ayesha Md, Babu DR. Estimation of genetic diversity in foxtail millet (Setaria italica (L.) Beauv.) germplasm using principal component analysis. Int. J. Chem. Stud 2018;6(5):2580-2583.

15. Priya ChS, Babu DR, Rajesh AP, Satyanarayana NH, Kumar VM, Rao VS. Multivariant analysis using principal component analysis for various traits in Mungbean. J. Pharmacogn. Phytochem 2019;8(5):24252429. 